\title{
Chlorine in swimming pools
}

To the Editor: As a former competitive swimmer who is now involved in the health and fitness industry, I am often approached by swimmers and coaches to get my opinion on the water quality in swimming pools used for training by competitive swimmers. Many swimming clubs train in heated indoor pools, mostly in a gym environment, and most of the swimmers complain of a number of symptoms such as sinus problems, itchy skin and itchy ear channels as a result of spending several hours per week exposed to chlorinated water.

The scientific literature around the topic of swimming and water quality focuses on asthma and allergies caused by chlorine in swimming pools. However, none of the studies mention any normative values for chemical levels in swimming pools.

The German Swimming Association (Deutscher Schwimm Verband (DSV)) conforms to European standards. According to them the norm values for free chlorine levels in swimming pools should be $0.3-0.6 \mathrm{mg} / \mathrm{l}$ for an indoor swimming pool. Interestingly enough, the Canadian norms are quite different from the European standards. They set values for free chlorine in an indoor swimming pool at $0.8-2.0 \mathrm{mg} / \mathrm{l}$. Chlorine levels of South African swimming pools in a gym environment have been reported to be around 2.0 $\mathrm{mg} / \mathrm{l}$ and fall into the higher range of the abovementioned standards. These higher chlorine levels result in a drop in the $\mathrm{pH}$ of the water below the recommended value (7.2 - 7.8), which causes additional irritation to the skin, ear, nose and eyes.

I remember suffering from the above symptoms during my competitive years. While eyes can be protected by goggles, the rest of a swimmer's body is exposed to the water. From my experience most of these symptoms are caused by elevated chlorine levels. Chlorine helps to keep the water hygienic, which, understandably, is the main concern of each gym environment. However, while it doesn't cause any harm to someone spending only 30 minutes in the water every now and then, swimmers spending several hours per week in this water often report the symptoms. I would assume that most gym environments act in the interest of their overall member base and put hygiene standards above the possible side-effects that only present for those few members spending long hours in the water.

My recommendations for the competitive swimmers who spend several hours a week in the water are to firstly wash the body with soap several times straight after you get out of the water. Choose a brand of soap appropriate for sensitive skin (i.e. neutral $\mathrm{pH}$ ). This advice sounds simple, but it worked for me and for my training colleagues. It sometimes took 4 - 5 washes before we were able to get rid of the chlorine smell on our skin - only then we knew we had got all of it off (and yes, even wash and rinse the ear channels as far as you can!). Secondly, use moisturising body lotion. One of the reasons for itchy skin is that the water dries out the skin. Together with the body wash the application of moisturising lotion should at least relieve any skin symptoms. Sinus problems could be relieved by wearing a nose clip during swimming. However, this is something not every swimmer feels comfortable with, as it might require a change in breathing habits.

Chlorine seems to be the only option for managing and ensuring a safe and hygienic pool environment. Until alternative and costeffective methods are found swimmers are forced to deal with the side-effects of their training environment.

\section{Lieselotte Maria Schoeler}

UCT/MRC Research Unit for Exercise Science and Sports Medicine

Sports Science Institute of SA

Newlands 7700

Cape Town, South Africa

E-mail: lotte.schoeler@virginactivelifecare.co.za

\section{Recommended reading}

AboutSwimming.com: http://swimming.about.com/lr/asthma_ and_swimming/107989/3/

Canadian Legal Information Institute: http://www.canlii.org/qc/ laws/regu/q-2r.18.1.02/20070307/whole.html. Document: Water quality in swimming pools and other artificial pools, Regulation respecting, R.Q. c. Q-2, r.18.1.02

DSV, Deutscher Schwimm Verband: www.dsv.de

\section{Sports medicine practitio- ners and SASMA poorly represented at Olympic and Paralympic Games}

To the Editor: The year 2008 has seen the summer Olympic and Paralympic Games being held in Beijing, Peoples Republic of China.

The South African Sports Medicine Association (SASMA) is the most representative body for sports medicine health care professionals in South Africa. It is multidisciplinary and should naturally attract those who have an interest in sports medicine. It also affords membership to the International Sports Medicine Federation (FIMS). I analysed the composition of the medical teams - servicing Team South Africa - that represented South Africa at the Olympic and Paralympic Games in 2008, and their membership status of SASMA.

There were, at the time of the Games, 268 registered members of SASMA. The table on p. 30 shows the composition of the respective teams.

This simple analysis reveals that statistically, even though the total number of 'sports' practitioners in South Africa is unknown, only $54 \%$ of sports health care practitioners at the Olympic and Paralympic Games were SASMA members. Without debating the composition of the team, only doctors and physiotherapists accompanied the Olympic and Paralympic athletes. The teams were appointed by the South African Sports Confederation and Olympic Committee (SASCOC). Potential team members were invited to apply and, using a rating system, the medical team was selected.

The result must be seen in light of, and in spite of, the fact that being a SASMA member carries credits in the assessment of team selection, and that invitations for applicants are primarily through SASMA channels. Another forum of selection are recommendations 


\begin{tabular}{lccccc} 
& $\begin{array}{l}\text { Olympic } \\
\text { Games }\end{array}$ & $\begin{array}{l}\text { Paralympic } \\
\text { Games }\end{array}$ & $\begin{array}{l}\text { Medical } \\
\text { team }\end{array}$ & $\begin{array}{l}\text { SASMA } \\
\text { members }\end{array}$ & $\begin{array}{l}\text { SASMA members } \\
\text { (\% of total) }\end{array}$ \\
\hline Doctors & 4 & 2 & 6 & 4 & 67 \\
Physiotherapists & 11 & 7 & 18 & 9 & 50 \\
$\quad$ Total & 15 & 9 & 24 & 13 & 54 \\
& & & & $\begin{array}{l}\text { (Olympics 53) } \\
\text { (Paralympics 56) }\end{array}$
\end{tabular}

from national federations - usually with regard to practitioners who are involved in the federation. This is indeed a poor reflection, and we need to look critically at possible reasons and address them.

Some reasons could include the following and should be addressed, debated and explored: the credibility of SASMA is not appreciated; ignorance as to the existence and value of SASMA; SASCOC does not afford adequate credibility to SASMA; lack of trust or belief in SASMA; and other potential factors.

As a starting point, it is necessary to engage with and increase the knowledge base of national federations, SASCOC, the National Department of Sport and Recreation, provincial departments of sport, and health care professionals. It is known that many 'sports physicians', 'sports physiotherapists', and other health care providers who practise the majority of their clinical work in the field of sports medicine are not members of SASMA. Perhaps they feel that SASMA has nothing (new) to offer them, or that they have nothing new to learn or gain by being members. They clearly do not consider that they could in fact contribute to SASMA.

I believe that health care providers, not only in Olympic and Paralympic teams, but in all sports federations and competitions, should be sought through the SASMA community, hence drawing attention to the current situation.

\section{Dr Demitri Constantinou}

Centre for Exercise Science and Sports Medicine

FIFA Centre of Excellence

School of Therapeutic Sciences

University of the Witwatersrand

Johannesburg

E-mail: Demitri.constantinou@wits.ac.za 